\title{
Strain-specific probiotic properties of lactic acid bacteria and their interference with human intestinal pathogens invasion
}

\author{
Raffaella Campana ${ }^{1}$, Saskia van Hemert ${ }^{2 *}$ (i) and Wally Baffone ${ }^{1}$
}

\begin{abstract}
Background: One of the working mechanisms of probiotic bacteria is their ability to compete with pathogens. To define the probiotic properties of seven Lactic Acid Bacteria (LAB) strains, we tested them for survival in simulated gastro-intestinal conditions, antimicrobial activities, co-aggregative abilities, and interferences studies against five human intestinal pathogens (Salmonella enteritidis ATCC 13076, Listeria monocytogenes ATCC 7644, Escherichia coli O157: H7 ATCC 35150, Cronobacter sakazakii ATCC 29544 and Campylobacter jejuni ATCC 33291).

Results: The LAB strains were able to survive the stomach simulated conditions, and varied in their abilities to survive the small intestinal-simulated conditions. The strains showed antibiotic susceptibility profiles with values equal or below the breakpoints set by the European Food and Safety Authority. The LAB cell-free cultures supernatants showed antimicrobial activities, with inhibition zones ranging from 10.0 to $17.2 \mathrm{~mm}$. All the LAB strains showed moderate auto-aggregation abilities while the greatest co-aggregation abilities were observed for Bifidobacterium bifidum W23, Lactobacillus plantarum W21 and Lactobacillus rhamnosus W71. The individual LAB strains showed strain-specific abilities to reduce the invasion of intestinal pathogens in an interference model with Caco-2 cells. Increased invasion inhibition was found when different combinations of $\angle A B$ strains were used in the interference tests.
\end{abstract}

Conclusion: The LAB strains examined in this study may protect the intestinal epithelium through a series of barriers (antimicrobial activity, co-aggregation with pathogens, adherence) and interference mechanisms. Consequently, these LAB strains may be considered candidates for prophylactic use to prevent intestinal infections.

Keywords: Lactic acid bacteria, Probiotic properties, Interference, Gut pathogens

\section{Background}

The infectious diseases caused by food-borne pathogens are a serious public health threat as reported by Centers for Disease Control and Prevention (CDC) and Foodborne Diseases Active Surveillance Network (FoodNet) [1]. Food spoilage-inducing bacterial pathogens such as Escherichia coli O157: H7 (EHEC), Salmonella, Listeria monocytogenes, and Campylobacter cause numerous illnesses and deaths, and huge economical loss [2]. Diarrhea, often caused by these pathogens, is the second leading cause of death in children under 5 years old and kills over 2 million people overall, per year [3]. Whereas

\footnotetext{
*Correspondence: s.vanhemert@winclove.nl

${ }^{2}$ Winclove Probiotics, Amsterdam, The Netherlands

Full list of author information is available at the end of the article
}

most of the deaths occur in developing countries, also in developed countries a lot of foodborne and waterborne infectious illnesses occur, with up to 1 in 6 of Americans affected yearly [4]. Treatment is mainly done by oral rehydration solution and anti-motility agents like loperamide are used widely [4]. Commonly used synthetic antibiotics are efficient in limiting the growth of food-borne pathogens, but a growing numbers of antibiotic-resistance among those human pathogens have been documented [5].

Probiotic bacteria represent a potential alternative in the prevention and control of food-borne infections, since they have proven effectiveness in reversing the pathogenicity of food-borne pathogens. Probiotics are defined as live microorganisms that confer a health benefit on 
the host when administered in adequate amounts [6, 7]. Strains of lactic acid bacteria (LAB) belonging to the genera Lactobacillus and Bifidobacterium are commonly used as probiotics [8]. The mechanisms underlying the activity of LAB strains against bacterial pathogens appear to be multifactorial and include the production of hydrogen peroxide, lactic acid, bacteriocin-like molecules, stimulation of the immune system, and modulation of intestinal microbiota [9-11]. Moreover, LAB can prevent the adhesion of pathogens by competing for the binding sites on the intestinal epithelial cells and consequently, reduce the colonization, thereby preventing the onset of infection [12-14]. In order to extent beneficial effects, probiotics need to achieve in the intestine an adequate biomass through growth, biofilm formation or aggregation and, consequently, the ability to aggregate is a desirable property for probiotics. In addition, micro-organisms with the ability to co-aggregate with other bacteria, such as pathogens, may have an advantage over the non-coaggregating bacteria that are easily removed from the intestinal gut [15].

Dietary intervention through food or food supplements containing live microbes with the aforementioned properties could be a possible step to improve the intestinal health status of people and to prevent infectious diarrhoea caused by food-borne pathogens. However, it is well-known that different bacterial strains of the same genus and species may exert completely different effects on the host [16]. Therefore, the specific properties of individual strains should be well-defined and the effect on health of each strain should be demonstrated in a case-by-case manner.

For these reasons, the potential probiotic properties of different LAB strains against Salmonella enteritidis ATCC 13076, L. monocytogenes ATCC 7644, E. coli O157: H7 ATCC 35150, Cronobacter sakazakii ATCC 29544 and Campylobacter jejuni ATCC 33291 were determined in this study. The experimental design was subdivided in two distinct phases in order to: (i) determine the strainspecific probiotic properties of the different $L A B$, evaluating their antimicrobial activity as well as auto- and co-aggregation properties; (ii) study the interference of selected LAB strains and their combinations against the invasion ability of human intestinal pathogens.

\section{Methods}

\section{Bacterial strains and culture conditions}

Seven strains of lactic acid bacteria (from the probiotic formulation WincloveTravel), kindly provided by Winclove Probiotics (The Netherlands), were used in this study: Bifidobacterium bifidum W23 (DSM 26331), Lactobacillus salivarius W24 (DSM 26403), Lactobacillus acidophilus W37 (DSM 26412), Lactobacillus casei W56
(DSM 26388), Lactococcus lactis W58 (DSM 26390), Lactobacillus plantarum W21 (DSM 26401) and Lactobacillus rhamnosus W71 (DSM 26396). These seven lactic acid strains are deposited at the DSMZ culture collection. They have been identified based on the highest match of a partial DNA sequence of the small subunit (16S) ribosomal RNA gene of the tested strain with the sequences of different LAB species, in the database of the Ribosomal Database Project II (RDP release 9.56), or based on repPCR fingerprint profile similarity to a reference culture that was identified as such based on the highest match of a partial DNA sequence of the small subunit (16S) Ribosomal RNA gene of the tested strain with the sequence of different LAB species in the database of the Ribosomal Database Project II (RDP release 9.56).

All the probiotic strains were grown on Man Rogosa Sharpe agar (MRS, Oxoid, Milan, Italy) for 24-48 h at $37{ }^{\circ} \mathrm{C}$ under microaerophilic conditions $\left(5 \% \mathrm{O}_{2} ; 10 \%\right.$ $\mathrm{CO}_{2}, 85 \% \mathrm{~N}_{2}$ ); B. bifidum W23 was grown in MRS with the addition of $0.05 \%$ cysteine in the same culture conditions. For interference studies, five reference human intestinal pathogens S. enteritidis ATCC 13076, L. monocytogenes ATCC 7644, E. coli O157: H7 ATCC 35150, C. sakazakii ATCC 29544 and C. jejuni ATCC 33291, were included. All pathogenic strains were grown in Tryptic Soy agar (TSA, Oxoid) at $37^{\circ} \mathrm{C}$ for $24 \mathrm{~h}$, while C. jejuni ATCC 33291 was grown on Columbia Agar Base (Oxoid) with 5\% Laked Horse Blood (Oxoid) and Campylobacter Growth supplement (Oxoid) at $37{ }^{\circ} \mathrm{C}$ for $48 \mathrm{~h}$ under microaerophilic conditions. All lactic acid bacteria and pathogenic strains were stored at $-80{ }^{\circ} \mathrm{C}$ in Nutrient Broth No. 2 (Oxoid) with $20 \%$ of glycerol.

\section{pH and bile tolerance tests}

The survival of the lactic acid bacteria to simulated gastro-intestinal (GI) tract conditions was investigated as described previously [17]. Briefly, each lyophilized strain $\left(2 \mathrm{~g}, 10^{9} \mathrm{CFU} / \mathrm{gr}\right)$ was rehydrated in $100 \mathrm{ml}$ of demineralized water for $15 \mathrm{~min}$ at room temperature. The rest of the experiment was performed at $37{ }^{\circ} \mathrm{C}$ in a water bath. The stomach was simulated by adding $1 \mathrm{ml}$ of porcine pepsin solution $(7 \mathrm{mg} / \mathrm{ml}$ porcine gastric mucosa $\mathrm{p} 7000$, Sigma) and decreasing the $\mathrm{pH}$ in four steps of $15 \mathrm{~min}$ to $4.8,4.5,3.5$ and 2.5 . After $75 \mathrm{~min}$, the entry into the proximal duodenum was mimicked by increasing the $\mathrm{pH}$ to 6.5 by adding $0.1 \mathrm{~N} \mathrm{NaOH}$ and, after $90 \mathrm{~min}, 10 \mathrm{ml}$ of porcine bile extract solution $(80 \mathrm{mg} / \mathrm{ml}$ of bile extract, Sigma) and $2 \mathrm{ml}$ of porcine pancreatin solution $(50 \mathrm{mg} /$ $\mathrm{ml}$ pancreatin, Sigma) were added. After $3 \mathrm{~h}$, bile salts were deactivated by adding $11.5 \mathrm{mM}$ of calcium chloride. The $\mathrm{pH}$ was maintained at 6.5 until $6 \mathrm{~h}$, which was the end of the experiment. Samples for the total cell count analysis were taken at the different time points, diluted in 
phosphate buffered saline and plated in several dilutions on MRS agar plates. Plates were incubated for $48-72 \mathrm{~h}$ at $37^{\circ} \mathrm{C}$ and thereafter the colony forming units $(\mathrm{CFU} / \mathrm{ml})$ were counted. The experiments have been performed in triplicate.

\section{Antibiotic susceptibility testing}

The antibiotic resistance for all the LAB strains used in this study was checked by the broth micro dilutions method. The bacteria were tested for resistance against ampicillin, vancomycin, gentamycin, kanamycin, streptomycin, erythromycin, clindamycin, tetracycline and chloramphenicol (VetMIC Lact-1 and 2 micro-dilution plates). The bacteria were plated onto MRS agar plates and grown for 24-48 h. A single colony of each strain was diluted in saline solution (McFarland 0.5) and distributed over 96 wells microtiter plates with LAB susceptibility medium [18] and different concentrations of antibiotics with a final bacterial load of $10^{5} \mathrm{CFU} / \mathrm{ml}$. The plates were incubated at $37{ }^{\circ} \mathrm{C}$ for $24 \mathrm{~h}$. The Minimal Inhibitory Concentration (MIC) was determined as the lowest concentration of a given antibiotic at which no growth of the tested organism was observed and compared with the breakpoints set by the European Safety and Food Authority [19].

\section{Preparation of pathogen strain inoculums}

Pathogen strains represented by $S$. enteritidis ATCC 13076, L. monocytogenes ATCC 7644, E. coli O157: H7 ATCC 35150, C. sakazakii ATCC 29544 were grown in Tryptic Soy Broth (TSB) (Oxoid) at $37{ }^{\circ} \mathrm{C}$ for $24 \mathrm{~h}$, while C. jejuni ATCC 33291 was grown in Mueller-Hinton Broth (MHB) (Oxoid) supplemented with $5 \%$ of Fetal Calf Serum (FCS) (Sigma) with gentle shaking (120 rpm) at $37{ }^{\circ} \mathrm{C}$ for $48 \mathrm{~h}$ under microaerophilic conditions. At the end of the incubation period, for each experiment, the bacterial cultures were centrifuged at $3500 \mathrm{rpm}$ for $15 \mathrm{~min}$, resuspended in the adequate culture media and adjusted to a turbidity of about $10^{8} \mathrm{CFU} / \mathrm{ml}$ by spectrophotometer reader using $\mathrm{OD}_{660}$ for C. jejuni ATCC 33291 and $\mathrm{OD}_{610}$ for all the other intestinal pathogens $[20,21]$.

\section{Antimicrobial activity of LAB "cell-free cultures supernatants"}

For the "cell-free cultures supernatant" (CFCS) extraction, the lactic acid bacteria were inoculated into $100 \mathrm{ml}$ of MRS broth at $37{ }^{\circ} \mathrm{C}$ for $48 \mathrm{~h}$ under microaerophilic conditions. The obtained cultures were centrifuged at $12,000 \mathrm{rpm}$ for $15 \mathrm{~min}$ at $4{ }^{\circ} \mathrm{C}$ and the supernatants (CFCSs), adjusted to $\mathrm{pH} 6.5$, were filtered with pore size $0.22 \mu \mathrm{m}$ membranes and stored at $-20^{\circ} \mathrm{C}$ until use.

The antibacterial properties of the CFCSs was determined using the agar well diffusion method (AWDM). Briefly, the pathogenic strains were grown overnight in
TSB at $37^{\circ} \mathrm{C}$ and then $500 \mu \mathrm{l}$ of each culture $\left(10^{7} \mathrm{CFU} /\right.$ $\mathrm{ml}$ ) were added to $25 \mathrm{ml}$ of Nutrient Agar. The plates were let solidify at room temperature for $20 \mathrm{~min}$; subsequently, on their surface, $6 \mathrm{~mm}$ holes were aseptically created. Finally, each well was filled with $50 \mu \mathrm{l}$ of the different CFCSs and the plates were incubated at $37{ }^{\circ} \mathrm{C}$ for $24 \mathrm{~h}$. After incubation, the zones of growth inhibition around each well, considered index of antimicrobial activity of the CFCSs, were measured and registered. Each experiment was performed in triplicate.

\section{Aggregative abilities of $L A B$ strains}

Auto-aggregation and co-aggregation abilities of each $\mathrm{LAB}$ strain were evaluated. For auto-aggregation ability, LAB strains were grown in MRS broth at $37^{\circ} \mathrm{C}$ for $24 \mathrm{~h}$ under microaerophilic conditions, as described above. Then, the bacterial cultures were centrifuged at $3500 \mathrm{rpm}$ for $10 \mathrm{~min}$ and the bacteria were resuspended in $10 \mathrm{ml}$ of PBS to approximately $10^{8} \mathrm{CFU} / \mathrm{ml}\left(\mathrm{OD}_{550} 0.2-0.3\right)$. Each suspension was vortexed for $10 \mathrm{~s}$ and incubated for $6 \mathrm{~h}$ at room temperature. At each hour, $1 \mathrm{ml}$ of the upper part of each suspension was withdrawn to measure the absorbance at $600 \mathrm{~nm}$. The percentage of auto-aggregation was then calculated according to the following formula:

$$
\text { auto-aggregation }(\%)=1-\left(\mathrm{A}_{\mathrm{t}} / \mathrm{A}_{0}\right) \times 100
$$

where $A_{t}$ is the absorbance at different time points and $\mathrm{A}_{0}$ the initial one.

For co-aggregation abilities, 2-ml aliquots of pairs of bacterial suspensions (probiotic and pathogen) were vortexed for $10 \mathrm{~s}$. Samples containing 4-ml aliquots of a single bacterial suspension were used as control. Each suspension was vortexed for $10 \mathrm{~s}$ and incubated for $6 \mathrm{~h}$ at room temperature. At each hour, $1 \mathrm{ml}$ of the upper part of each suspension was withdrawn to measure the absorbance as described above. The co-aggregation percentages were finally calculated as follow:

$$
\% \text { Coaggregation }=\frac{\left(\left(\mathrm{A}_{x}+\mathrm{A}_{y}\right) / 2\right)-\mathrm{A}(x+y)}{\mathrm{A}_{x}+\mathrm{A}_{y} / 2} \times 100
$$

where $\mathrm{A}_{\mathrm{x}}$ and $\mathrm{A}_{\mathrm{y}}$ are the individual aggregation properties of the lactobacilli and the pathogen, and $\mathrm{A}(\mathrm{x}+\mathrm{y})$ is the combined aggregation of the lactobacilli and the pathogen. All the experiments were performed in duplicate.

\section{Cell cultures}

Caco-2 cells, human colon carcinoma cells, were grown routinely in $25 \mathrm{~cm}^{2}$ flasks containing approximately $6 \mathrm{ml}$ of D-MEM (Sigma) supplemented with 10\% Fetal Calf Serum (FCS) (Sigma), 1\% of non-essential amino acids (Sigma) and $1 \%$ of antibiotics (penicillin and streptomycin) (Sigma) at $37{ }^{\circ} \mathrm{C}$ with $5 \% \mathrm{CO}_{2}$. For all the 
experiments, Caco-2 cells were treated with trypsin, seeded at a ratio of $2 \times 10^{4} \mathrm{cells} / \mathrm{ml}$ in 6 -well plates and used as differentiated cells after 15 days in culture. Before the assays, the cell monolayers were washed twice with phosphate buffered saline (PBS) pH 7.2

\section{Adhesive properties of LAB strains on Caco-2 cells}

The adhesive properties of $L A B$ strains were evaluated on Caco-2 monolayers prepared as described above. Briefly, a loopful of each LAB strain was transferred into a sterile glass tube containing $10 \mathrm{ml}$ of MRS broth; for B. bifdum W23 was used MRS broth with $0.05 \%$ of cystein. All tubes were then incubated at $37{ }^{\circ} \mathrm{C}$ for $24 \mathrm{~h}$ under microaerophilic conditions. At the end of incubation, the bacterial cultures were centrifuged at $3500 \mathrm{rpm}$ for $10 \mathrm{~min}$ and resuspended in D-MEM with 1\% FCS. The bacterial density of each culture was adjusted to $\mathrm{OD}_{600}$ of $0.9-1$ corresponding to about $10^{8} \mathrm{CFU} / \mathrm{ml}$. These suspensions were co-incubated with Caco-2 monolayers for $1 \mathrm{~h}$ at $37{ }^{\circ} \mathrm{C}$ in $5 \% \mathrm{CO}_{2}$. After the incubation period, supernatants were discarded and the monolayers were softly washed twice with phosphate saline buffer (PBS) to remove the non-attached bacteria. The monolayers were finally trypsinized to release the eukaryotic cells and adhered bacteria; after appropriate serial dilutions in physiological saline solution, the number of adhered bacteria was enumerated on MRS agar after incubation at $37^{\circ} \mathrm{C}$ for $24 \mathrm{~h}$ under microerophilic conditions. Results were expressed as the percentage of bacteria adhered with respect to the amount of bacteria added (\% CFU bacteria adhered/CFU bacteria added) [15].

\section{Invasion inhibition by interference studies with selected LAB strains and their combinations}

Interference assays were carried out using B. bifidum W23, L. salivarius W24 and L. rhamnosus W71; each selected on the basis of their adhesive and aggregative abilities. Exclusion and competition tests were used as infection schemes on Caco-2 cell monolayers with specific time of infection for each pathogen: $2 \mathrm{~h}$ for $S$. enteritidis ATCC 13076 and $L$. monocytogenes ATCC 7644, 3 h for E. coli O157: H7 ATCC 35150 and C. sakazakii ATCC 29544, 4 h for C. jejuni ATCC 33291. The bacterial suspensions of LAB and pathogen strains were prepared as described above.

For the exclusion test, Caco-2 monolayers were infected with $1 \mathrm{ml}$ of each LAB suspension for $1 \mathrm{~h}$ and then washed with PBS to remove non-adherent bacteria; at this point, $1 \mathrm{ml}$ of each pathogenic suspension was added to cells monolayers for the appropriate incubation time at $37{ }^{\circ} \mathrm{C}$ with $5 \%$ of $\mathrm{CO}_{2}$. At the end of incubation, cells were washed 3-5 times with PBS, treated with D-MEM gentamicin solution $(250 \mu \mathrm{g} / \mathrm{ml})$ for $2 \mathrm{~h}$ and lysed with Triton X-100 (0.5\% in PBS). Finally, cell lysates were serially diluted in physiological saline solution, plated on the adequate agar and incubated in the appropriate culture condition for the $\mathrm{CFU} / \mathrm{ml}$ enumeration.

For the competition test, cells were exposed to a mixed suspension $(1: 1)$ of each pathogen with each LAB strain. After the appropriate incubation times at $37{ }^{\circ} \mathrm{C}$ with $5 \%$ of $\mathrm{CO}_{2}$, monolayers were washed 3-5 times with PBS, treated with D-MEM gentamicin solution $(250 \mu \mathrm{g} / \mathrm{ml})$, washed with PBS, and lysed with Triton X-100 (0.5\% in PBS). The lysates were then serially-diluted in saline, and plated on the adequate agar and incubated in the culture condition for $\mathrm{CFU} / \mathrm{ml}$ enumeration.

Subsequently, for each pathogen, the exclusion and competition exposure schemes were performed using the four following $\mathrm{LAB}$ strains combinations:

i. B. bifidum $\mathrm{W} 23+$ L. salivarius $\mathrm{W} 24$

ii. B. bifidum W23 + L. rhamnosus W71

iii. L. salivarius W24 + L. rhamnosus W71

iv. B. bifidum $\mathrm{W} 23+$ L. salivarius $\mathrm{W} 24+$ L. rhamnosus W71

The interference studies were performed as described above with the difference that Caco- 2 cells were infected with pathogens and each LAB combination. Infection on Caco-2 cells, gentamicin killing protection assay, cellular lysis and viable counts were carried out as previously described.

All the interference assays were performed in duplicate.

\section{Statistical analysis}

Statistical analysis was performed using Prism 5.0 (GraphPad Software, Inc., La Jolla, USA). The conditions necessary to perform parametric tests were checked before conducting the analysis, otherwise non-parametric tests were utilized. The level of significance was considered $\alpha=0.05$.

\section{Results}

\section{Strain-specific probiotic properties}

The in vitro GI survival data for the seven $L A B$ strains are shown in Fig. 1. All the strains showed good survival to the simulated stomach conditions. In particular, $L$. acidophilus W37 showed a reduction of approximately one $\log \mathrm{CFU} / \mathrm{ml}$, while the other strains had a much lower reduction of $\mathrm{CFU} / \mathrm{ml}$. The ability to survive to the simulated conditions of the small intestinal differed between the strains. In detail, L. acidophilus W37, L. rhamnosus W71, and L. salivarius W24 were unable to survive in this in vitro GI model, while L. casei W56 and L. lactis W58 showed a reduction of $3 \log C F U / \mathrm{ml}$, and L. plantarum W21 of $1.5 \log$ CFU/ml. Finally, B. bifidum W23 showed only a twofold reduction of $\mathrm{CFU} / \mathrm{ml}$ value at the end of the experiment (Fig. 1). 


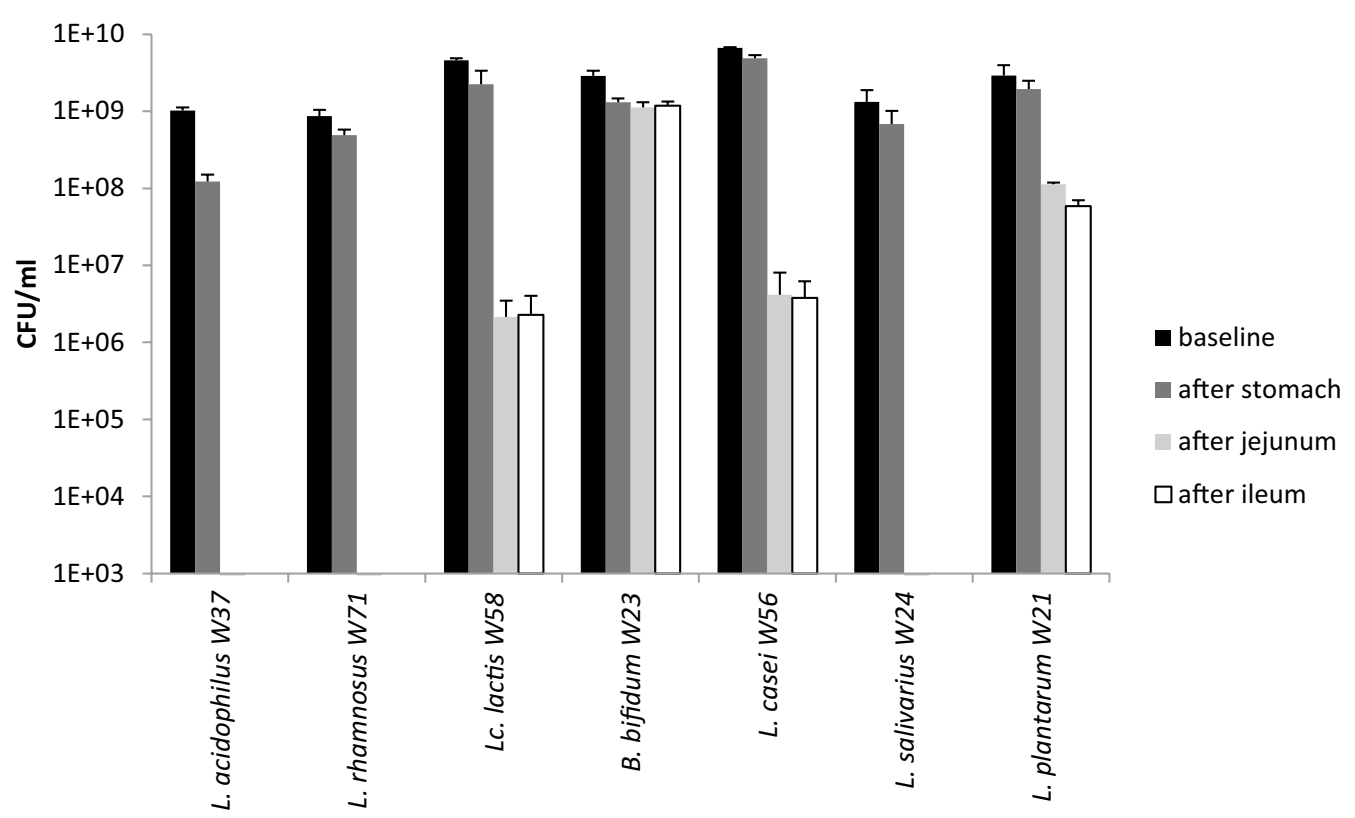

Fig. 1 In vitro Gl survival data of $L A B$ strains. Each lyophilized strain $\left(2 \mathrm{~g}, 10^{9} \mathrm{CFU} / \mathrm{gr}\right.$ ) was rehydrated in $100 \mathrm{ml}$ of demineralized water for $15 \mathrm{~min}$ at room temperature (baseline). The rest of the experiment was performed at $37^{\circ} \mathrm{C}$. The stomach was simulated by adding $1 \mathrm{ml}$ of porcine pepsine solution and decreasing the $\mathrm{pH}$ in four steps of $15 \mathrm{~min}$ to 4.8, 4.5, 3.5 and 2.5. After $75 \mathrm{~min}$ (stomach), the entry into the proximal duodenum was mimicked by increasing the $\mathrm{pH}$ to 6.5 by adding $0.1 \mathrm{~N} \mathrm{NaOH}$ and, after $90 \mathrm{~min}, 10 \mathrm{ml}$ of porcine bile extract solution and $2 \mathrm{ml}$ of porcine pancreatin solution were added. After $3 \mathrm{~h}$ (duodenum), bile salts were deactivated by adding $11.5 \mathrm{mM}$ of calcium chloride. The pH was maintained at 6.5 until $6 \mathrm{~h}$ (ileum) which was the end of the experiment. The experiments have been performed in triplicate

The minimal inhibitory concentrations of nine different antibiotics for the seven LAB strains are summarized in Table 1; all values are equal or below the breakpoints set by the European Food and Safety Authority.

\section{Antimicrobial activity of CFCSs against food-borne pathogens}

The antimicrobial effect of CFCSs extracted from each $\mathrm{LAB}$ strain against selected food-borne pathogens are summarized in Table 2. The CFCSs tested in this experiment were able to inhibit the growth of intestinal pathogens with a variable degree of antibacterial activity. In fact, the CFCSs of L. lactis W58, L. plantarum W21, and L. rhamnosus W71 showed a wide antimicrobial activity against all the food-borne pathogens included in this study, whilst the others CFCSs have demonstrated a limited or absent antimicrobial activity.

Specifically, the greatest zones of growth inhibition, $17.2 \pm 0.21$ and $17.1 \pm 0.21 \mathrm{~mm}$, were reached by the CFCS of L. rhamnosus W71 and L. casei W56 toward C. jejuni ATCC 33291, the microorganism resulted more sensitive to all the examined CFCSs. The activity

Table 1 Minimum inhibitory concentrations (MIC, $\mathrm{mg} / \mathrm{l}$ ) of the tested LAB strains for nine different antibiotics

\begin{tabular}{lrllllrrrr}
\hline & Amp & Van & Gen & Kan & Strep & \multicolumn{1}{c}{ Ery } & Clin & Tetra & Chlo \\
\hline B. bifidum W23 & $0.06[2]$ & $1[2]$ & $64[64]$ & n.r. & $32[128]$ & $0.25[1]$ & $0.12[1]$ & $2[8]$ & $2[4]$ \\
L. acidophilus W37 & $0.094[1]$ & $0.5[2]$ & $1[16]$ & $32[64]$ & $3[16]$ & $0.016[1]$ & $0.094[1]$ & $0.38[4]$ & $1.5[4]$ \\
L. caseiW56 & $0.5[4]$ & n.r. & $4[32]$ & $64[64]$ & $32[64]$ & $0.25[1]$ & $0.12[1]$ & $2[4]$ & $8[4]$ \\
L. plantarum W21 & $0.5[2]$ & n.r. & $8[16]$ & $64[64]$ & n.r. & $0.5[1]$ & $2[2]$ & $32[32]$ & $4[8]$ \\
L. rhamnosus W71 & $4[4]$ & n.r. & $2[16]$ & $32[64]$ & $8[32]$ & $0.12[1]$ & $0.5[1]$ & $1[8]$ & $4[4]$ \\
L. salivarius W24 & $1[4]$ & n.r. & $2[16]$ & $64[64]$ & $32[64]$ & $0.25[1]$ & $0.25[1]$ & $4[8]$ & $4[4]$ \\
L. lactis W58 & $0.25[2]$ & $0.25[4]$ & $2[32]$ & $8[64]$ & $16[32]$ & $0.12[1]$ & $0.12[1]$ & $1[4]$ & $4[8]$ \\
\hline
\end{tabular}

In square brackets are indicated the microbial breakpoint according to the European Food and Safety Authority [19]. Strains with MICs higher that the breakpoint are considered resistant

Amp ampicillin, Van vancomycin, Gen gentamycin, Kan kanamycin, Strep streptomycin, Ery erythromycin, Clin clindamycin, Tetra tetracycline, Chlo chloramphenicol, n.r. not required 
Table 2 Antimicrobial activity of the cell-free supernatants (CFCSs) produced by the different LAB strains toward human intestinal pathogens strains performed by agar well diffusion method

\begin{tabular}{llllll}
\hline CFCSs & \multicolumn{5}{l}{ Inhibition zone $(\mathbf{m m} \pm \mathbf{~ s d})$} \\
\cline { 2 - 6 } & $\begin{array}{l}\text { S. enteritidis } \\
\text { ATCC 13076 }\end{array}$ & $\begin{array}{l}\text { L. monocytogenes } \\
\text { ATCC 7644 }\end{array}$ & $\begin{array}{l}\text { E. coli O157: H7 } \\
\text { ATCC 35150 }\end{array}$ & $\begin{array}{l}\text { C. sakazakii } \\
\text { ATCC 29544 }\end{array}$ & $\begin{array}{l}\text { C. jejuni } \\
\text { ATCC 33291 }\end{array}$ \\
\hline B. bifidum W23 & - & $10.1 \pm 0.25$ & $11.0 \pm 0.35$ & $12.1 \pm 0.25$ & $12.1 \pm 0.32$ \\
L. salivarius W24 & $10.1 \pm 0.32$ & - & - & $10.2 \pm 0.11$ & $10.1 \pm 0.28$ \\
L. acidophilus W37 & - & $11.1 \pm 0.12$ & - & - & $12.1 \pm 0.36$ \\
L. casei W56 & - & $11.1 \pm 0.51$ & - & $10.2 \pm 0.21$ & $17.1 \pm 0.21$ \\
L. lactis W58 & $11.0 \pm 0.15$ & $11.0 \pm 0.27$ & $12.0 \pm 0.28$ & $11.1 \pm 0.15$ & $10.5 \pm 0.51$ \\
L. plantarum W21 & $10.1 \pm 0.31$ & $14.1 \pm 0.34$ & $10.0 \pm 0.20$ & $10.1 \pm 0.28$ & $13.5 \pm 0.52$ \\
L. rhamnosus W71 & $10.1 \pm 0.24$ & $12.1 \pm 0.31$ & $11.0 \pm 0.15$ & $10.2 \pm 0.25$ & $17.2 \pm 0.21$ \\
Positive control & $16.3 \pm 0.53$ (Gen) & $19.3 \pm 0.63$ (W) & $15.6 \pm 0.64$ (Gen) & $16.3 \pm 0.52$ (Strep) & $32 \pm 0.51$ (Gen) \\
\hline
\end{tabular}

Gen gentamicin $10 \mu \mathrm{g}, W$ trimethoprim $5 \mu \mathrm{g}$, Strep streptomycin $10 \mu \mathrm{g}$, - no visible growth inhibition

of CFCSs against the others four food-borne pathogens showed lower zones of growth inhibition.

\section{Aggregation abilities and adhesiveness of LAB strains}

The auto- and co-aggregation abilities of the LAB strains are summarized in Table 3. After $6 \mathrm{~h}$ of incubation, the highest percentages of aggregation were seen for B. bifidum W23 and L. rhamnosus W71 (21.37 and 21.08\% respectively). All the LAB demonstrated auto-aggregation ability higher than those showed by intestinal pathogens, whose percentage values ranging from a minimum of $10.30 \%$ for $E$. coli O157: H7 ATCC 35150 to a maximum of $12.90 \%$ for $S$. enteritidis ATCC 13076. Regarding the co-aggregation abilities, the LAB strains that showed the strongest co-aggregation after $6 \mathrm{~h}$ of incubation were B. bifidum W23, L. plantarum W21 and L. rhamnosus W71. Specifically, B. bifidum W23 showed the highest coaggregation ability with C. jejuni ATCC 33291 (18.14\%), L. plantarum W21 with S. enteritidis ATCC 13076 (16.79\%), and L. rhamnosus W71 with E. coli O157: H7 ATCC 35150 (17.41\%). All the probiotic strains were able to co-aggregate with C. jejuni ATCC 33291, except L. acidophilus W37 and L. lactis W58 (4.33 and 3.42\%).

The adhesion abilities of each LAB strain on Caco-2 cell monolayers are represented in Fig. 2. In general, the examined LAB presented good adhesion ability to intestinal cells with strain-specific characteristics. More specifically, B. bifidum W23 showed the highest adhesion index (\% CFU bacteria adhered/CFU bacteria added) of $51 \%$, while the others strains evidenced adhesion indexes ranging from $25 \%$ for $L$. salivarius W24 to $9.5 \%$ for $L$. rhamnosus W71.

\section{Interference of LAB strains on intestinal pathogens invasion ability}

The capacity of B. bifidum W23, L. salivarius W24, and L. rhamnosus W71 to inhibit the intestinal food-borne pathogens invasion on Caco-2 cells, selected on the basis of their adhesion index and aggregative abilities, was determined using exclusion and competition tests. The interference studies against each intestinal pathogen were performed using LAB strains singularly and four different

Table 3 Percentages of auto- and co-aggregation abilities of the different LAB strains with intestinal pathogens

\begin{tabular}{|c|c|c|c|c|c|c|}
\hline & \multirow[t]{2}{*}{ Auto-aggregation } & \multicolumn{5}{|c|}{ Co-aggregation with pathogens } \\
\hline & & $\begin{array}{l}\text { S. enteritidis } \\
\text { ATCC } 13076\end{array}$ & $\begin{array}{l}\text { L. monocytogenes } \\
\text { ATCC } 7644\end{array}$ & $\begin{array}{l}\text { E. coli 0157: H7 } \\
\text { ATCC } 35150\end{array}$ & $\begin{array}{l}\text { C. sakazakii } \\
\text { ATCC } 51329\end{array}$ & $\begin{array}{l}\text { C. jejuni } \\
\text { ATCC } 33291\end{array}$ \\
\hline B. bifidum W23 & $21.37( \pm 1.12)$ & $14.86( \pm 0.28)$ & $11.96( \pm 0.20)$ & $10.27( \pm 0.31)$ & $10.07( \pm 0.28)$ & $18.14( \pm 1.02)$ \\
\hline L. salivarius W24 & $19.33( \pm 1.81)$ & $6.82( \pm 0.20)$ & $8.33( \pm 0.12)$ & $10.31( \pm 0.21)$ & $7.06( \pm 0.22)$ & $15.84( \pm 0.32)$ \\
\hline L. acidophilus W37 & $15.90( \pm 1.20)$ & $14.2( \pm 0.19)$ & $8.35( \pm 0.11)$ & $3.85( \pm 0.01)$ & $9.52( \pm 0.19)$ & $4.33( \pm 0.02)$ \\
\hline L.caseiW56 & $15.92( \pm 1.72)$ & $6.34( \pm 0.11)$ & $5.14( \pm 0.15)$ & $5.64( \pm 0.14)$ & $5.34( \pm 0.11)$ & $13.94( \pm 0.32)$ \\
\hline L. lactis W58 & $15.50( \pm 1.21)$ & $13.94( \pm 0.31)$ & $7.13( \pm 0.13)$ & $9.32( \pm 0.21)$ & $4.54( \pm 0.31)$ & $3.42( \pm 0.28)$ \\
\hline L.plantarum W21 & $15.03( \pm 1.61)$ & $16.79( \pm 0.35)$ & $14.62( \pm 0.31)$ & $12.01( \pm 0.24)$ & $4.72( \pm 0.34)$ & $13.00( \pm 0.21)$ \\
\hline L. rhamnosus W71 & $21.08( \pm 1.83)$ & $15.93( \pm 0.24)$ & $13.73( \pm 0.22)$ & $17.4( \pm 0.22)$ & $12.51( \pm 0.26)$ & $11.00( \pm 0.23)$ \\
\hline
\end{tabular}

Data were obtained after $6 \mathrm{~h}$ of incubation at room temperature. Data are expressed as mean \pm SD 


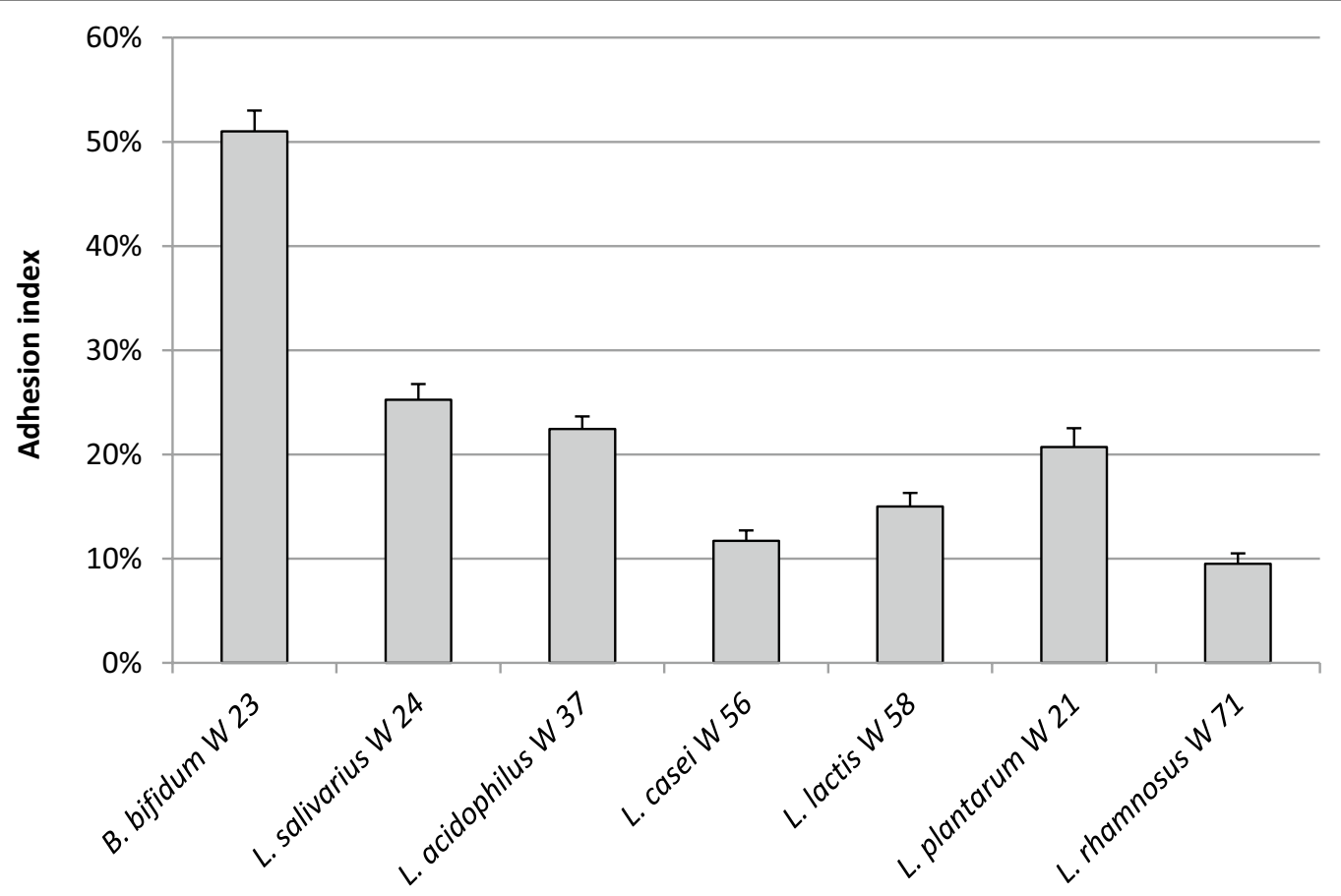

Fig. 2 Adhesion ability of the different $L A B$ strains to the human Caco-2 cell monolayers. Caco-2 monolayers were incubated for $1 \mathrm{~h}$ with a $L A B$ strain. Thereafter the supernatants were discarded and the monolayers were washed to remove the non-attached bacteria. Then the monolayers were trypsinized to release the eukaryotic cells and adhered bacteria and the bacteria were plated on MRS plates. Results are expressed as the percentage of bacteria adhered with respect to the amount of bacteria added (\% CFU bacteria adhered/CFU bacteria added). The experiments have been performed in triplicate

combinations of LAB strains as described in "Methods" section.

As a general trend, each tested LAB strain was able to inhibit the invasiveness of S. enteritidis ATCC 13076, L. monocytogenes ATCC 7644, E. coli O157: H7 ATCC 35150, C. sakazakii ATCC 29544 and C. jejuni ATCC 33291 with a variable degree dependent on the bacterial species (Fig. 3). Each single LAB strain showed weak ability to reduce the invasion of S. enteritidis ATCC 13076 on Caco-2 cells. The LAB combinations provoked a higher decrease of internalized S. enteritidis ATCC 13076 in both the interference tests (Fig. 3a).

The three single LAB strains demonstrated good interference activity against the invasion ability of $L$. monocytogenes ATCC 7644 (Fig. 3b), with a remarkable decrease of recovered internalized bacteria after gentamicin protection assay on Caco- 2 cell monolayers. Statistically significant ( $\mathrm{p}$ value $<0.05$ ) reductions of $L$. monocytogenes ATCC 7644 numbers were registered in the interference tests with all the four LAB combinations.

The tested LAB strains were also able inhibit the invasion ability of E. coli O157: H7 ATCC 35150 (Fig. 3c). As observed for the others tested intestinal pathogens, the four LAB combinations induced a more remarkable decrease of the internalized E. coli O157: H7 ATCC
35150 in comparison with the individual strains. The single LAB strains were able to weakly interfere with Caco-2 invasion ability of C. sakazakii ATCC 29544 (Fig. 3d), and $4.48 \log$ CFU/ml, a statistically significant decrease of the recovered internalized bacteria, was registered only in the exclusion test performed with L. rhamnosus W71, compared to $5.30 \log \mathrm{CFU} / \mathrm{ml}$ of the control internalized C. sakazakii ATCC 29544. In the interference studies carried out with the four LAB combinations, the most considerable decrease of the internalized $C$. sakazakii ATCC 29544 (4.75 log CFU/ml) was obtained in the exclusion tests with the combination formed by B. bifidum W23 and $L$. salivarius W24 and in the competition test with that formed by B. bifidum W23, L. salivarius W24 and $L$. rhamnosus W71.

Finally, regarding C. jejuni ATCC 33291, the obtained results indicated that each single $\mathrm{LAB}$ strains inhibited the invasion ability of C. jejuni ATCC 33291 (Fig. 3e). In detail, statistically significant reductions of the internalized C. jejuni ATCC 33291, compared to the control ones (6.52 $\log \mathrm{CFU} / \mathrm{ml})$, were registered in the exclusion test with B. bifidum W23 (5.24 $\log \mathrm{CFU} / \mathrm{ml})$ or L. rhamnosus W71 (5.01 $\log \mathrm{CFU} / \mathrm{ml})$, while the lowest values of internalized C. jejuni ATCC 33291 was evidenced in the competition test with L. rhamnosus W71 (4.48 log CFU/ml). 

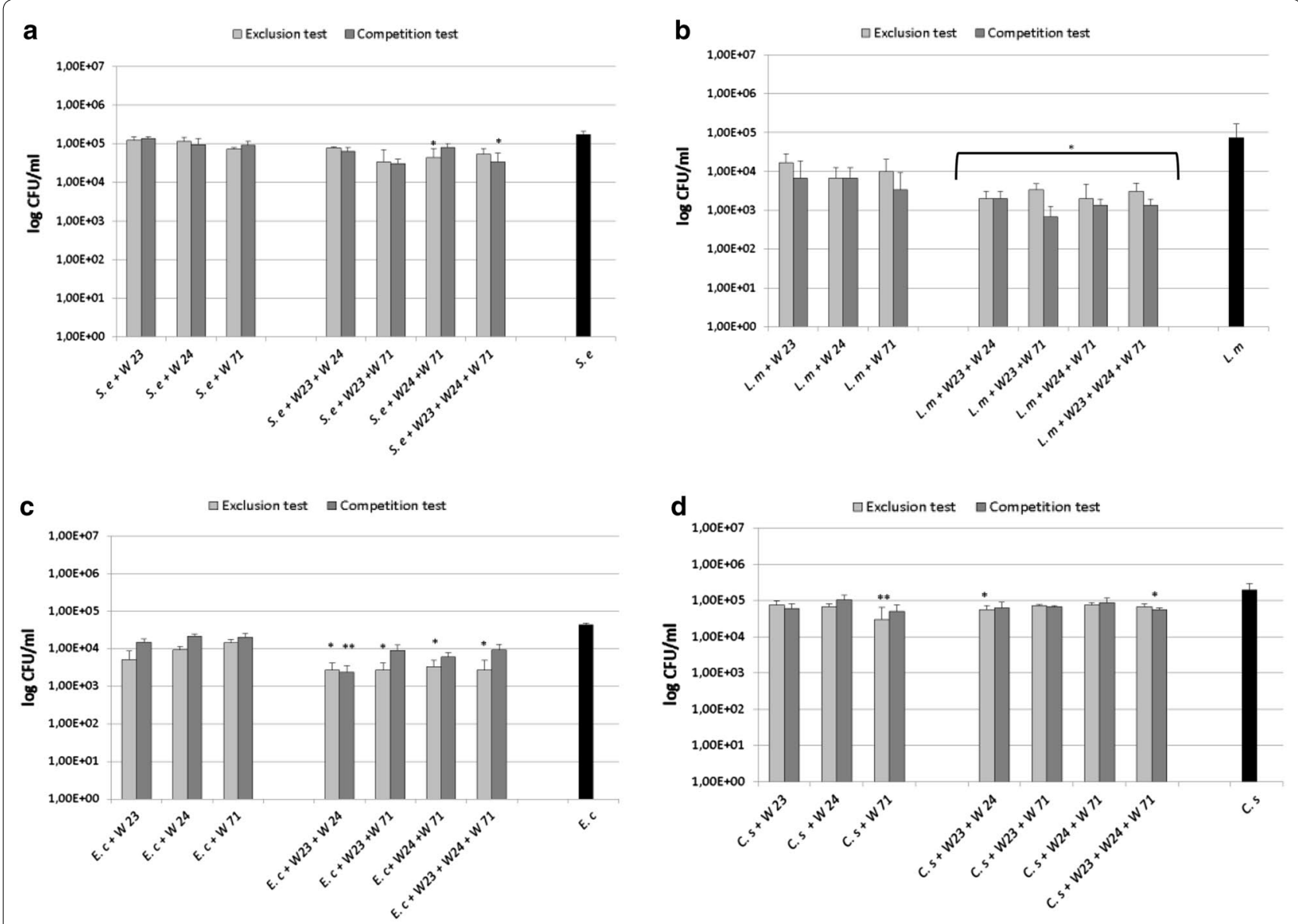

e

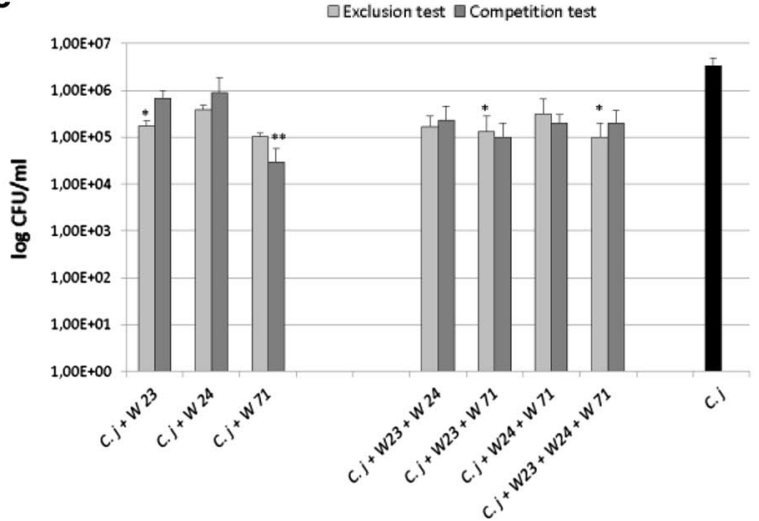

Fig. 3 Invasion inhibition of human intestinal pathogens by single LAB strains and their four combinations. a S. enteritidis ATCC 13076, b L. monocytogenes ATCC 7644, c E. coli O157: H7 ATCC 35150, d C. sakazakii ATCC 29544, e C. jejuni ATCC 33291. Asterisks represented values statistically significant $(p<0.05)$ in comparison to the control group (Kruskal-Wallis non parametric test)

The four LAB combinations were also able to considerably reduce the number of internalized C. jejuni ATCC 33291.

The findings for all pathogens and all tested LAB strains and combination are summarized in Table 4.

\section{Discussion}

Probiotic characterization of each LAB strain

The ability to survive an in vitro GI model varied between the tested LAB strains. Strain specific tolerance to stomach acidity and/or GI survival has been shown before 
Table 4 Invasion inhibition of single LAB strains and their combinations against human intestinal pathogens

\begin{tabular}{|c|c|c|c|c|c|c|c|}
\hline \multirow[t]{2}{*}{ Strains and interference test } & \multicolumn{3}{|c|}{ Single LAB strains } & \multicolumn{4}{|c|}{ LAB combinations } \\
\hline & W23 & W24 & W71 & $W 23+W 24$ & $W 23+W 71$ & W24 + W71 & $W 23+W 24+W 71$ \\
\hline \multicolumn{8}{|l|}{ S. enteritidis ATCC 13076} \\
\hline Exclusion (\%) & 27.92 & 31.82 & 57.14 & 55.19 & 80.52 & 74.68 & 68.83 \\
\hline Competition (\%) & 20.13 & 45.45 & 47.40 & 62.99 & 82.47 & 53.25 & 80.52 \\
\hline \multicolumn{8}{|l|}{ L. monocytogenes ATCC 7644} \\
\hline Exclusion (\%) & 76.94 & 90.78 & 86.16 & 97.23 & 95.39 & 97.23 & 95.85 \\
\hline Competition (\%) & 90.78 & 90.78 & 95.39 & 97.23 & 99.08 & 98.16 & 98.16 \\
\hline \multicolumn{8}{|l|}{ E. coli O157:H7 ATCC 35150} \\
\hline Exclusion (\%) & 88.11 & 77.95 & 66.14 & 93.70 & 93.70 & 92.13 & 93.70 \\
\hline Competition (\%) & 65.35 & 49.61 & 52.76 & 94.49 & 78.74 & 85.83 & 77.95 \\
\hline \multicolumn{8}{|l|}{ C. sakazakii ATCC 29544} \\
\hline Exclusion (\%) & 56.19 & 61.90 & 82.86 & 71.67 & 63.33 & 61.67 & 66.67 \\
\hline Competition (\%) & 65.71 & 23.81 & 52.38 & 68.33 & 66.67 & 56.67 & 71.67 \\
\hline \multicolumn{8}{|l|}{ C. jejuni ATCC 33291} \\
\hline Exclusion (\%) & 94.80 & 88.30 & 96.90 & 95.00 & 96.00 & 90.70 & 97.00 \\
\hline Competition (\%) & 80.00 & 73.00 & 99.10 & 93.00 & 97.00 & 94.00 & 94.00 \\
\hline
\end{tabular}

$[17,22,23]$. Surprisingly, the main decrease in viable was found in the simulated conditions of small intestinal, and not under the acid stomach conditions. In general most LAB appear to possess a natural ability to survive pancreatin [24, 25]. In contrast pancreatin tolerance, bile tolerance is strain-specific [26], so this might cause the observed differences is survival. In vivo, the amount of bile shows high variability to time, along the length of the GI tract and amongst individuals, and the conditions in our in vitro model might not adequately reflect the in vivo situation, where food matrices might help survival of the bacteria.

Antibiotic resistance and transferability of antibiotic resistance genes from probiotic strains to commensal microbiota in the gut are important components of the safety of bacteria used as probiotics [27]. No antibiotic resistance was found in these commercial available LAB strains for the EFSA panel of antibiotics, whereas this has been found in some other studies [28]. These latter results highlights the importance of antimicrobial susceptibility testing as part of the safety analysis of potential probiotic strains.

In the present study different LAB strains were evaluated for their ability to antagonize human intestinal pathogens by secretion of antimicrobial compounds, interference with bacterial growth and interference with pathogens during adhesion/invasion process on epithelial cells. The antimicrobial activity of the CFCS of seven $L A B$ strains against five intestinal pathogens was first determined by agar well diffusion method; as reported, two strains, L. casei W56 and L. rhamnosus
W71, showed relative strong antibacterial activity (inhibition zone $>15 \mathrm{~mm}$ ) and all the others strains moderate activity (inhibition zone between 10 and $15 \mathrm{~mm}$ ) against the tested pathogens. As these cultured broths were neutralized to $\mathrm{pH} 6.5$, the inhibitory activity to pathogenic bacteria is probably due to production of antibacterial molecules rather than to the acidic conditions of the cultural media. Our data are in agreement with several studies referring antimicrobial activity of LAB strains $[29,30]$. Whether this is due to production of organic acids (e.g., lactic acid and acetic acid), hydrogen peroxide, bacteriocins or other compounds was not investigated in our study.

Other important properties, linked to beneficial effects of probiotics, are the auto-aggregation and the co-aggregation, defined as the accumulation of bacteria of the same species and the accumulation of bacteria of different species respectively. These properties are fundamental for probiotics since auto-aggregation seems to be correlated with the adherence to epithelial cells [15, 31], a prerequisite for colonization and persistence in the gastrointestinal tract, while co-aggregation represents a barrier to prevent intestinal surface colonization of pathogenic microorganisms [32]. It has been suggested that cellular aggregation could be positive in promoting the colonization of beneficial micro-organisms, as reported for lactobacilli in the gastrointestinal or vaginal tract $[33,34]$. In our study, the LAB strains showed relatively higher auto-aggregation compared to intestinal pathogens, suggesting that this property may allow them to survive at sufficiently high number and colonize the 
gastrointestinal tract. All the LAB strains tested showed co-aggregation abilities with pathogens, with percentages depended on the strain (probiotic and pathogen strains) and time of co-incubation. All the LAB strains showed co-aggregation and aggregation abilities, in particular $B$. bifidum W23 and L. rhamnosus W71. Our results are in agreement with Collado et al. [15], who reported a correlation between auto-aggregation and co-aggregation properties. In addition, our results suggest that the ability of LAB to promote co-aggregation with pathogens and to compete for adhesion to the epithelial cell surface is strain-dependent, probably related with the presence of specific molecules in the LAB surface acting either as ligands binding pathogens and/or as adhesins for attachment to epithelial cells [35].

Since the binding to epithelial cells is valuable for probiotic bacteria, we also determined the ability of our LAB strains to adhere to Caco-2 intestinal cells. The adhesion index of the tested strains showed a variability depending on the strain, species and genera; in fact, the most adhesive strain resulted to be $B$. bifidum W23, while, among the Lactobacillus spp., the observed adhesion properties differs from species to species. Our data are consistent with studies carried out on the LAB adhesion, showing that this ability was strain-specific and varied within the same species [36-38].

\section{Interference studies between LAB and intestinal pathogens}

To colonize the human gastrointestinal (GI) tract, pathogen bacteria must compete with gut resident microbiota, such as lactic acid bacteria that play crucial roles in maintaining the microbial ecosystem of the GI by preventing colonization and infection of incoming bacterial pathogens $[8,12-14]$. It is very important to underline that potential probiotic strains are unique and strains of the same genus and species may have different beneficial effects [14]. In addition, it is assumed that the combinations of specific probiotic strains potentiate the beneficial effects to the host compared to the probiotic strains alone [39]. In this study, after determining the specific properties of individual LAB strains, three strains and their four combinations were selected and tested for their ability to inhibit the invasiveness of $S$. enteritidis ATCC 13076, L. monocytogenes ATCC 7644, E. coli O157: H7 ATCC 35150, C. sakazakii ATCC 29544 and C. jejuni ATCC 33291 on Caco-2 monolayers. The LAB selection showed the following specific probiotic properties: $B$. bifidum W23 possessed moderate auto-aggregative and co-aggregative abilities, high antimicrobial activity, and high adhesion index; $L$. salivarius W24 showed moderate auto-aggregative and weak co-aggregative abilities, high antimicrobial ability, and medium adhesion index; while
L. rhamnosus W71 had high auto-aggregative and coaggregative abilities, moderate antimicrobial activity, and low adhesion index. Our data demonstrated that each $\mathrm{LAB}$ was able to reduce the invasion ability of intestinal pathogens; this is in agreement with other studies reporting the protective effect of lactic acid bacteria against Salmonella spp., L. monocytogenes, and C. jejuni [13, 40-42].

The ability to inhibit the invasion of intestinal pathogens indicates a very high strain-specificity. In fact, $B$. bifidum W23 and L. rhamnosus W71 were able to reduce the invasion of the tested pathogens by exclusion as well as by competition, while L. salivarius W24 prevalently appeared to operate exclusively via exclusion. Regarding the putative mechanisms of bacterial antagonism, coaggregation could be one probiotic mechanism of action to prevent the attachment of pathogens to the intestinal surface and avoid its binding to the cellular line [13, 43]. In our case, B. bifidum W23 and L. rhamnosus W71 both co-aggregated well and reduced the invasion of the intestinal pathogens L. monocytogenes ATCC 7644 and $C$. jejuni ATCC 33291. On the contrary, L. salivarius W24 did not appear to use co-aggregation as its mechanism of action to reduce the invasion of L. monocytogenes ATCC 7644 and C. jejuni ATCC 33291. These results support the hypothesis that there are multiple mechanisms by which probiotics exert antagonistic action against intestinal pathogens, and since surface components of LAB are implicated in adhesion, co-aggregation and bacteria-bacteria interactions, these phenomena could be probably interrelated.

According to the hypothesis that a combination of LAB strains may be more effective in vivo than single strains $[7,35]$, we found increased percentages of invasion inhibition by the four LAB strain combinations compared to those of the individual LAB strains. Particularly interesting is the case of S. enteritidis ATCC 13076; in fact, when tested against this pathogen, the individual LAB strains reached low percentages of invasion inhibition (maximum value $57.14 \%$ by $L$. rhamnosus W71 in the exclusion test), whilst the LAB combinations achieved a greater cumulative percentage of invasion inhibition up to $82.47 \%$. Similarly, regarding C. sakazakii ATCC 29544, the LAB combinations have reached higher percentages of invasion inhibition, even whilst most cases of the single LAB strains have gained good results (up to $82.86 \%$ of invasion inhibition). These findings demonstrate that the tested LAB combinations possess probiotic properties, supporting the hypothesis that the use of probiotic combinations, selected for their strain-specific characteristics, may increase the beneficial effects on human health $[9,39]$.

To our knowledge, this is the first work where LAB strains were tested individually as well as in combination 
by in vitro interference tests with intestinal pathogens. To verify the ability of different LAB strains, also in their combinations, to inhibit the invasion of pathogenic bacteria appears important for the selection of new probiotic microorganisms. For these reasons, the tested LAB may be potential candidates to develop new probiotic combinations to prevent or treat infections by a specific pathogen.

\section{Conclusions}

LAB strains with good abilities to adhere to epithelial cells could be better suited to colonize the intestine. They can act as a barrier to fight pathogens through different competitive mechanisms, like antimicrobial activity, co-aggregation with pathogens, and adherence. For this, among the tested LAB strains, B. bifidum W23, $L$. salivarius W24 and L. rhamnosus W71 have the best characteristics showing good antimicrobial activity as well as high interference activity with pathogen invasion. In addition, the LAB combinations, with enhanced antagonizing activity against the tested intestinal pathogens, confirm the importance of specific probiotic combinations to potentiate the beneficial effects to the host (Additional file 1: Figure S1).

\section{Additional file}

Additional file 1: Figure S1. Representative images of $L A B$ strains adhesion to Caco-2 cells. (a) B. Bifidum W23, (b) L. salivarius W24, (c) L. acidophilus W37, (d) L. plantarum W21.

\section{Authors' contributions}

$\mathrm{RC}$ and WB conceived and designed experiments. RC and SvH performed the experiments and analyzed the data. RC wrote the initial draft of the manuscript, SvH and WB gave input on the manuscript. All authors read and approved the final manuscript.

\section{Author details}

${ }^{1}$ Division of Toxicological, Hygiene and Environmental Sciences, Department of Biomolecular Science, University of Urbino "Carlo Bo", Urbino, Italy. ${ }^{2}$ Winclove Probiotics, Amsterdam, The Netherlands.

\section{Acknowledgements}

We would like to thank Sebastiaan de Vos and Nick Neijendorf from Winclove Probiotics for technical assistance with the Gl survival assays.

\section{Competing interests}

$\mathrm{SvH}$ is employee of Winclove Probiotics. Winclove manufactures and markets probiotics. This author has no direct or additional financial interests. The other authors declare that they have no competing interests.

\section{Availability of data and materials}

All data generated or analysed during this study are included in this published article and its additional information file.

\section{Funding}

The authors received no specific funding for this work.

Received: 13 January 2017 Accepted: 28 February 2017

Published online: 06 March 2017
References

1. Centers for Disease Control and Prevention (CDC). Foodborne diseases active Surveillance Network (FoodNet): FoodNet surveillance report for 2012 (final report). Atlanta: CDC; 2014.

2. Centers for Disease Control and Prevention (CDC). Incidence and trends of infection with pathogens transmitted commonly through foodfoodborne diseases active surveillance network, 10 U.S. sites, 1996-2012. MMWR Morb Mortal Wkly Rep. 2013;62(15):283-7.

3. Dickinson B, Surawicz CM. Infectious diarrhea: an overview. Curr Gastroenterol Rep. 2014;16(8):399.

4. Munot K, Kotler DP. Small intestinal infections. Curr Gastroenterol Rep. 2016;18(6):31

5. Andersson DI, Hughes D. Antibiotic resistance and its cost: is it possible to reverse resistance? Nat Rev Microbiol. 2010;8(4):260-71.

6. Hill C, Guarner F, Reid G, Gibson GR, Merenstein DJ, Pot B, Morelli L, Canani RB, Flint HJ, Salminen S, Calder PC, Sanders ME. Expert consensus document: the International Scientific Association for Probiotics and Prebiotics consensus statement on the scope and appropriate use of the term probiotic. Nat Rev Gastroenterol Hepatol. 2014;11(8):506-14.

7. FAO/WHO working group. Report of a joint FAO/WHO expert consultation on evaluation of health and nutritional properties of probiotics in food including powder milk with live lactic acid bacteria. Córdoba, Argentina (October 1-4, 2001). 2001.

8. Salminen S, Nybom S, Meriluoto J, Collado MC, Vesterlund S, El-Nezami $\mathrm{H}$. Interaction of probiotics and pathogens-benefits to human health? Curr Opin Biotechnol. 2010;21(2):157-67.

9. Collado MC, Jalonen L, Meriluoto J, Salminen S. Protection mechanism of probiotic combination against human pathogens: in vitro adhesion to human intestinal mucus. Asia Pac J Clin Nutr. 2006;15(4):570-5.

10. Boge T, Remigy M, Vaudaine S, Tanguy J, Bourdet-Sicard R, van der Werf S. A probiotic fermented dairy drink improves antibody response to influenza vaccination in the elderly in two randomised controlled trials. Vaccine. 2009;27(41):5677-84.

11. Kang H-J, Im S-H. Probiotics as an immune modulator. J Nutr Sci Vitaminol. 2015;61(Supplement):S103-5.

12. Campana R, Federici S, Ciandrini E, Baffone W. Antagonistic activity of Lactobacillus acidophilus ATCC 4356 on the growth and adhesion/ invasion characteristics of human Campylobacter jejuni. Curr Microbiol. 2012;64(4):371-8.

13. Garriga M, Rubio R, Aymerich T, Ruas-Madiedo P. Potentially probiotic and bioprotective lactic acid bacteria starter cultures antagonise the Listeria monocytogenes adhesion to HT29 colonocyte-like cells. Benef Microbes. 2015;6(3):337-43.

14. Abdel-Daim A, Hassouna N, Hafez M, Ashor MS, Aboulwafa MM. Antagonistic activity of Lactobacillus isolates against Salmonella typhi in vitro. Biomed Res Int. 2013;2013:680605.

15. Collado MC, Meriluoto J, Salminen S. Adhesion and aggregation properties of probiotic and pathogen strains. Eur Food Res Technol. 2008;226(5):1065-73.

16. Collado MC, Bauerl C, Perez-Martinez G. Defining the microbiota for developing new probiotics.Microb Ecol Health Dis. 2012;23(1):18579.

17. Timmerman HM, Niers LE, Ridwan BU, Koning CJ, Mulder L, Akkermans LM, Rombouts FM, Rijkers GT. Design of a multispecies probiotic mixture to prevent infectious complications in critically ill patients. Clin Nutr. 2007;26(4):450-9.

18. Klare I, Konstabel C, Muller-Bertling S, Reissbrodt R, Huys G, Vancanneyt M, Swings J, Goossens H, Witte W. Evaluation of new broth media for microdilution antibiotic susceptibility testing of Lactobacilli, Pediococci, Lactococci, and Bifidobacteria. Appl Environ Microbiol. 2005;71(12):8982-6.

19. Panel EF. Guidance on the assessment of bacterial susceptibility to antimicrobials of human and veterinary importance. EFSA J. 2012;10(6):2740.

20. Fox JG, Rogers AB, Whary MT, Ge Z, Taylor NS, Xu S, Horwitz BH, Erdman SE. Gastroenteritis in NF-kB-deficient mice is produced with wild-type Camplyobacter jejuni but not with C. jejuni lacking cytolethal distending toxin despite persistent colonization with both strains. Infect Immun. 2004;72:1116-25.

21. Baffone W, Casaroli A, Citterio B, Pierfelici L, Campana R, Vittoria E, Guaglianone E, Donelli G. Campylobacter jejuni loss of culturability in aqueous microcosms and ability to resuscitate in a mouse model. Int J Food Microbiol. 2006;107:83-91. 
22. Berrada N, Lemeland JF, Laroche G, Thouvenot P, Piaia M. Bifidobacterium from fermented milks: survival during gastric transit. J Dairy Sci. 1991;74(2):409-13.

23. Matto J, Malinen E, Suihko ML, Alander M, Palva A, Saarela M. Genetic heterogeneity and functional properties of intestinal bifidobacteria. J Appl Microbiol. 2004;97(3):459-70.

24. Masco L, Crockaert C, Van Hoorde K, Swings J, Huys G. In vitro assessment of the gastrointestinal transit tolerance of taxonomic reference strains from human origin and probiotic product isolates of Bifidobacterium. J Dairy Sci. 2007;90(8):3572-8.

25. Charteris WP, Kelly PM, Morelli L, Collins JK. Development and application of an in vitro methodology to determine the transit tolerance of potentially probiotic Lactobacillus and Bifidobacterium species in the upper human gastrointestinal tract. J Appl Microbiol. 1998;84(5):759-68.

26. Chateau N, Deschamps A, Sassi AH. Heterogeneity of bile salts resistance in the Lactobacillus isolates of a probiotic consortium. Lett Appl Microbiol. 1994;18(1):42-4.

27. Sanders ME, Akkermans LM, Haller D, Hammerman C, Heimbach J, Hormannsperger G, Huys G, Levy DD, Lutgendorff F, Mack D, Phohirath P, Solano-Aguilar G, Vaughan E. Safety assessment of probiotics for human use. Gut Microbes. 2010;1(3):164-85.

28. Klare I, Konstabel C, Werner G, Huys G, Vankerckhoven V, Kahlmeter G, Hildebrandt B, Muller-Bertling S, Witte W, Goossens H. Antimicrobial susceptibilities of Lactobacillus, Pediococcus and Lactococcus human isolates and cultures intended for probiotic or nutritional use. J Antimicrob Chemother. 2007;59(5):900-12.

29. Servin AL. Antagonistic activities of lactobacilli and bifidobacteria against microbial pathogens. FEMS Microbiol Rev. 2004;28(4):405-40.

30. Marianelli C, Cifani N, Pasquali P. Evaluation of antimicrobial activity of probiotic bacteria against Salmonella enterica subsp. enterica serovar typhimurium 1344 in a common medium under different environmental conditions. Res Microbiol. 2010;161(8):673-80.

31. Del Re B, Sgorbati B, Miglioli M, Palenzona D. Adhesion, autoaggregation and hydrophobicity of 13 strains of Bifidobacterium longum. Lett Appl Microbiol. 2000;31(6):438-42.

32. Kos B, Suskovic J, Vukovic S, Simpraga M, Frece J, Matosic S. Adhesion and aggregation ability of probiotic strain Lactobacillus acidophilus M92. J Appl Microbiol. 2003;94(6):981-7.

33. Collado MC, Gueimonde M, Hernandez M, Sanz Y, Salminen S. Adhesion of selected Bifidobacterium strains to human intestinal mucus and the role of adhesion in enteropathogen exclusion. J Food Prot. 2005;68(12):2672-8.
34. Atassi F, Servin AL. Individual and co-operative roles of lactic acid and hydrogen peroxide in the killing activity of enteric strain Lactobacillus johnsonii NCC933 and vaginal strain Lactobacillus gasseri KS120.1 against enteric, uropathogenic and vaginosis-associated pathogens. FEMS Microbiol Lett. 2010;304(1):29-38.

35. Sengupta R, Altermann E, Anderson RC, McNabb WC, Moughan PJ, Roy NC. The role of cell surface architecture of lactobacilli in hostmicrobe interactions in the gastrointestinal tract. Mediat Inflamm. 2013;2013:237921.

36. Federici S, Ciarrocchi F, Campana R, Ciandrini E, Blasi G, Baffone W. Identification and functional traits of lactic acid bacteria isolated from Ciauscolo salami produced in Central Italy. Meat Sci. 2014;98(4):575-84.

37. Duary RK, Rajput YS, Batish VK, Grover S. Assessing the adhesion of putative indigenous probiotic lactobacilli to human colonic epithelial cells. Indian J Med Res. 2011;134(5):664-71.

38. Wang B, Wei H, Yuan J, Li Q, Li Y, Li N, Li J. Identification of a surface protein from Lactobacillus reuteri JCM1081 that adheres to porcine gastric mucin and human enterocyte-like HT-29 cells. Curr Microbiol. 2008;57(1):33-8.

39. Collado MC, Grzeskowiak L, Salminen S. Probiotic strains and their combination inhibit in vitro adhesion of pathogens to pig intestinal mucosa. Curr Microbiol. 2007;55(3):260-5.

40. Fayol-Messaoudi D, Coconnier-Polter MH, Moal VL, Atassi F, Berger CN, Servin AL. The Lactobacillus plantarum strain ACA-DC287 isolated from a Greek cheese demonstrates antagonistic activity in vitro and in vivo against Salmonella enterica serovar Typhimurium. J Appl Microbiol. 2007;103(3):657-65.

41. Winkelstroter LK, De Martinis EC. In vitro protective effect of lactic acid bacteria on Listeria monocytogenes adhesion and invasion of Caco-2 cells. Benef Microbes. 2015;6(4):535-42.

42. Wine E, Gareau MG, Johnson-Henry K, Sherman PM. Strain-specific probiotic (Lactobacillus helveticus) inhibition of Campylobacter jejuni invasion of human intestinal epithelial cells. FEMS Microbiol Lett. 2009;300(1):146-52.

43. $\mathrm{Xu} \mathrm{H}$, Jeong HS, Lee HY, Ahn J. Assessment of cell surface properties and adhesion potential of selected probiotic strains. Lett Appl Microbiol. 2009:49(4):434-42.

\section{Submit your next manuscript to BioMed Central and we will help you at every step:}

- We accept pre-submission inquiries

- Our selector tool helps you to find the most relevant journal

- We provide round the clock customer support

- Convenient online submission

- Thorough peer review

- Inclusion in PubMed and all major indexing services

- Maximum visibility for your research

Submit your manuscript at www.biomedcentral.com/submit 